\title{
Hemodialysis in Pregnant with Systemic Lupus Erythematosus: Case Report and Review
}

\author{
José Lucas Daza1, Yaroslad de la Cruz², John Fredy Galindo3, Luis Puello4, Gerardo Gutiérrez, \\ María Camila Correcha ${ }^{3}$, Carlos Alban ${ }^{3}$, Daniel Soto ${ }^{3}$, Andrés Cárdenas ${ }^{6}$, Luis José Daza ${ }^{7}$, \\ Néstor Guarnizo ${ }^{8}$, Abel Caraballo ${ }^{9}$
}

${ }^{1}$ Internist-Nephrologist, Ibague, Colombia

${ }^{2}$ Internist-Nephrologist, Cali, Colombia

${ }^{3}$ General Physician, Ibague, Colombia

${ }^{4}$ Internist-Nephrologist Cartagena, Colombia

${ }^{5}$ Internist-Nephrologist, Villavicencio, Colombia

${ }^{6}$ Medical Student, Santa Marta, Colombia

${ }^{7}$ Internist-Hematologist, Cartagena, Colombia

${ }^{8}$ General Physician, University of Tolima, Ibague

${ }^{9}$ Intensivist Phsysician, Barranquilla, Colombia

Email: montelucaz@gmail.com

How to cite this paper: Daza, J.L., de la Cruz, Y., Galindo, J.F., Puello, L., Gutiérrez, Z., Correcha, M.C., Alban, C., Soto, D., Cárdenas, A., Daza, L.J., Guarnizo, N. and Caraballo, A. (2022) Hemodialysis in Pregnant with Systemic Lupus Erythematosus: Case Report and Review. Open Journal of Nephrology, 12, 48-59.

https://doi.org/10.4236/ojneph.2022.121005

Received: December 25, 2021

Accepted: February 19, 2022

Published: February 22, 2022

Copyright (c) 2022 by author(s) and Scientific Research Publishing Inc. This work is licensed under the Creative Commons Attribution International License (CC BY 4.0).

http://creativecommons.org/licenses/by/4.0/ (c) (i) Open Access

\begin{abstract}
Systemic lupus erythematosus is an autoimmune disease with an etiopathogenesis that is still unclear. With a higher incidence in women of childbearing age. Pregnancy in patients suffering from this pathology is a constant challenge for multidisciplinary teams. The changes of pregnancy, especially to the immune system and the kidney, have repercussions on the renal compromise secondary to lupus. Lupus nephropathy is more active during pregnancy and leads to adverse outcomes for the mother-fetus binomial. The early identification of pregnant women with a higher risk of complications, access to health resources and the participation of a multidisciplinary team is the strategy that increases maternal-fetal survival. A report case of a 25 -year-old black female with SLE and a 10-week pregnancy who was admitted to the emergency department with criteria for dialysis. The literature focused on lupus nephritis and dialysis in pregnancy was reviewed. Articles were reviewed in databases such as PubMed, Cochrane, among others, focused on the topic of pregnancy with SLE and pregnancy with dialysis. A total of 15 review articles, 2 meta-analyses, 3 observational studies and 6 cohort studies ( 3 prospective and 3 retrospective) were filtered.
\end{abstract}

\section{Keywords}

Dialysis, Lupus Nephritis, Pregnancy, Renal Disease and Systemic Lupus 
Erythematous

\section{Introduction}

The course of a pregnancy is one of the main changes currently in patients with SLE (Systemic Lupus Erythematosus). In past decades, pregnancy was discouraged in patients with lupus, with special emphasis on those patients who had risk factors for developing kidney involvement and requiring the use of immunosuppressants or developing specific autoantibodies such as antiphospholipids and anti-Ro/SSA, La/SSBA. Current knowledge of the disease and its treatments have increased pregnancy success rates in patients with SLE, significantly improving care by a multidisciplinary team that promotes a successful pregnancy with few complications for the mother and fetus when the disease is present in remission. The approach consists of pre-pregnancy screening, SLE activity, specific medications, risk factors, and continues through lactation with significantly better results.

\section{Clinical Case Presentation}

A 25-year-old black female patient with a history of systemic lupus erythematosus and class VI lupus nephritis diagnosed in 2005; G3 A1 P1. She presents poor evolution and clinical response to treatment and in November 2006 she begins renal replacement therapy in the context of dialysis urgency. Family history of: SLE (sister), rheumatoid arthritis and hypothyroidism (parents) was evaluated by the nephrology service for a high-risk pregnancy.

Usual medication: Azathioprine $50 \mathrm{mg} /$ day, hydroxychloroquine $200 \mathrm{mg} / \mathrm{day}$, calcium carbonate 2 grams/day, weekly subcutaneous erythropoietin $8000 \mathrm{IU}$, calcitriol $0.25 \mathrm{mcg} /$ day, B complex one tablet a day. Physical exam: BP 110/60 mmHg, HR 72 bpm; FR: 12 rpm; Sat: 96\%; Weight: $47.8 \mathrm{Kg}$, diuresis: <200 ml/24 hours. Alert and oriented, mucocutaneous pallor, fair nutritional status, rhythmic heart sounds, adequate respiratory ventilation, gravid uterus. Gynecological examination: No pathological findings. No edema in extremities and pulses present.

Laboratories on admission to the service can be seen in Table 1; Doppler echocardiogram LVDD: 41 mm; LVSD: $24 \mathrm{~mm}$; RVSI: $10 \mathrm{~mm}$; PP: $8 \mathrm{~mm}$; LVSF: preserved, mild mitral and tricuspid insufficiency. Obstetric Ultrasound: Gestational age 10.2 weeks; Ovular sac with regular contours, embryo inside, $34 \mathrm{~mm}$ long. Evolution: Daily intermittent dialysis $\times 4$ hours is indicated, with an intensity of 24 hours per week. Target urea $<100 \mathrm{mg} / \mathrm{dl}$; Diet of $45 \mathrm{Kcal} / \mathrm{k} /$ day, folic acid $10 \mathrm{mg} /$ day; complex B one tab day; Erythropoietin 12,000 IU sc/weekly; Fetal lung maturation was performed with betamethasone at 34 weeks, achieving a 36-week pregnancy, with a cesarean delivery without complications.

\section{Discussion}

When correlating pregnancy and kidney disorders, we initially refer to the changes 
Table 1. Laboratory results.

\begin{tabular}{cccc}
\hline LABORATORY & VALUE & LABORATORY & VALUE \\
\hline Hemoglobin & $8 \mathrm{~g} / \mathrm{dl}$ & Calcium & $8.9 \mathrm{mg} / \mathrm{dl}$ \\
Hct & $23 \%$ & Phosphorus & $3.9 \mathrm{mg} / \mathrm{dl}$ \\
Leukocytes & $4700 \mathrm{cells} / \mathrm{mm}^{3}$ & PTH & $422 \mathrm{pg} / \mathrm{ml}$ \\
Platelets & $166,000 \mathrm{cells} / \mathrm{mm}^{3}$ & Vitamin D & $\mathrm{ng} / \mathrm{ml}$ \\
Urea & $127 \mathrm{mg} / \mathrm{dl}$ & Ferritin & $872 \mathrm{mcg} / \mathrm{dl}$ \\
Creatinine & $7.2 \mathrm{mg} / \mathrm{dl}$ & Transferrin saturation & $59 \%$ \\
$\mathrm{Na}$ & $137 \mathrm{mmol} / \mathrm{l}$ & Serum iron & $115 \mathrm{mcg} / \mathrm{dl}$ \\
$\mathrm{K}$ & $5.2 \mathrm{mmol} / \mathrm{l}$ & Albumin & $3.9 \mathrm{~g} / \mathrm{dl}$ \\
\hline
\end{tabular}

that occur during pregnancy. It is an anatomical and natural condition that entails physiological changes at the renal level. Some of the main ones are increased blood volume, decreased systemic vascular resistance, and increased cardiac output. There is an increase in nitric oxide and relaxin, as well as relative resistance to angiotensin II consistent with the decrease in systemic blood pressure with a nadir at 20 weeks of gestation. Glomerular filtration increases by $50 \%$ consistent with the decrease in serum creatinine in a range of 0.4 to $0.6 \mathrm{mg} / \mathrm{dL}$ due to hyperfiltration. Relaxed smooth muscle secondary to progesterone and mechanical compression by the growing uterus causes physiologic hydronephrosis and retention of urine in the collecting system. Urinary protein excretion increases to 180 to $250 \mathrm{mg} /$ day. High proteinuria in pregnancy has been established at a value higher than $300 \mathrm{mg} /$ day. This increase is attributed to hyperfiltration and changes in glomerular permeability. There are several changes in the function of the innate and adaptive immune systems that predispose to autoimmune diseases, such as frequent etiologies of impaired renal function in young women. Normal pregnancy is characterized by a shift from the $\mathrm{T}$ helper type response (TH1; cell-mediated immunity) to a TH2 phenotype (humoral response-mediated immunity), leading to tolerance to fetal antigens, trophoblast invasion, and placental formation. In autoimmune diseases, such as systemic lupus erythematosus (SLE), alterations in the number and function of regulatory $\mathrm{T}$ cells may correlate with an increased risk of pregnancy complications, such as preeclampsia, and poor fetal and maternal outcomes (Figure 1) [1].

Extrarenal lupus flares are more frequent in the second and third trimesters of pregnancy, evidence suggests that severe exacerbations are in 3\% to 5\% of pregnancies. Immune activity during conception seems to be the best predictor of renal flares (low levels of $\mathrm{C} 3$ and anti-DNA antibodies). The low dosage of C4 and the increased levels of anti-C1q antibodies are described in outbreaks during the first or second trimester of pregnancy with more frequency.

Systemic lupus erythematosus is a chronic multisystemic autoimmune disease with clinical variability that mainly affects women of childbearing age. Lupus nephritis usually occurs in 50\% during the course of the disease [2] [3] [4]. Adverse 

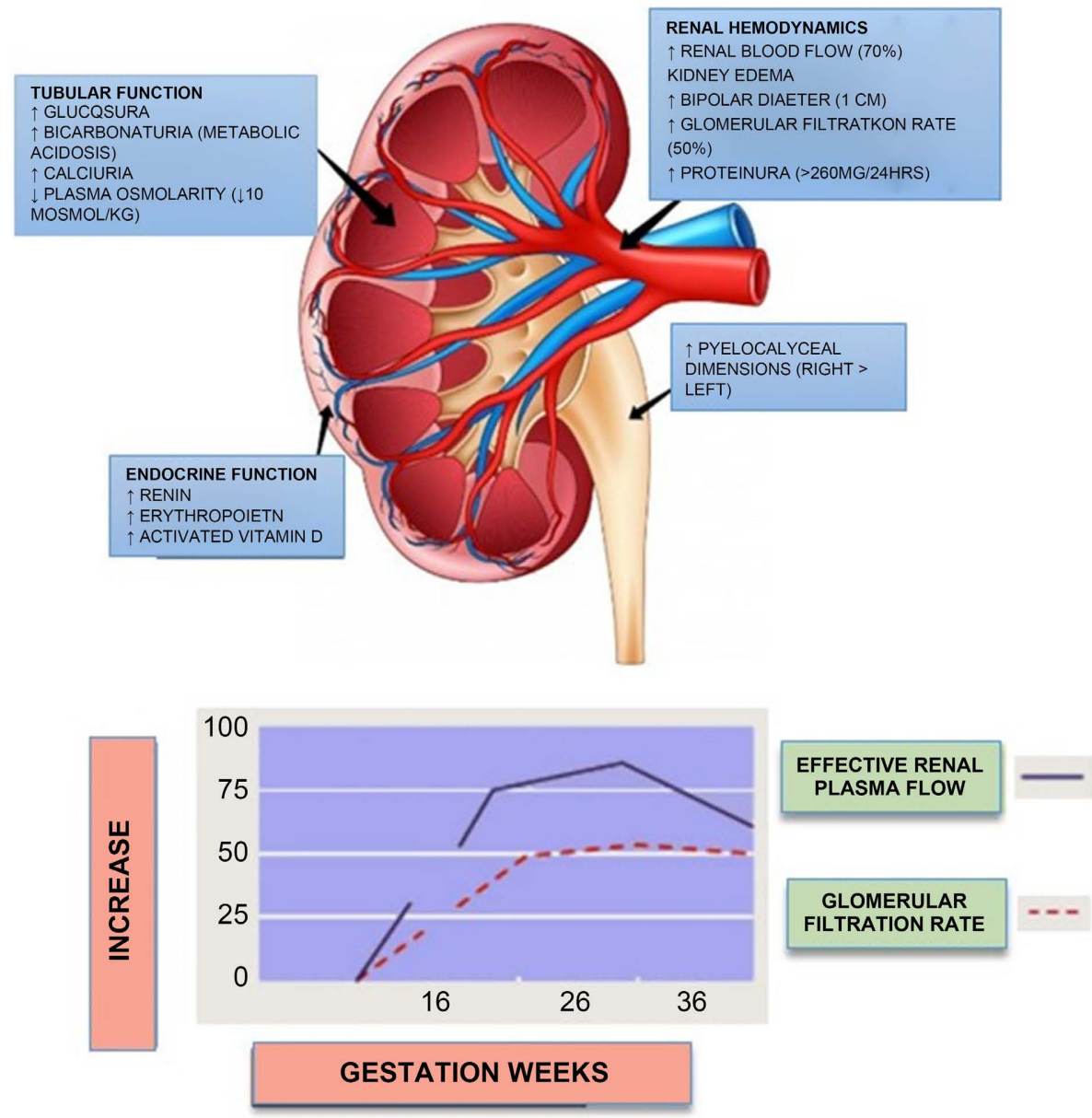

Figure 1. Renal PHYSIOLOGICAL changes during normal pregnancy.

risk factors during gestation are proteinuria $>1 \mathrm{gr} /$ day, arterial hypertension, previous or active lupus nephritis; and presence of antiphospholipid antibodies [5]. Complications during pregnancy that can be divided into maternal (lupus flares, impaired renal function, preeclampsia and thrombotic events) and/or fetal-neonatal (spontaneous abortion, premature birth, intrauterine growth retardation and neonatal lupus syndrome). It is important that the disease is inactive for at least 6 months before pregnancy [6] [7].

There are conflicting results in the literature regarding lupus flares. They are more common in pregnancy and it is probably due to the fact that clinical studies were carried out using different definitions of lupus flare, [8] it is difficult to differentiate the physiological changes typical of pregnancy from lupus flares, in particular with non-specific signs and symptoms of fatigue, arthralgia, hair loss, dyspnea, headache, peripheral edema, among others; Likewise, laboratory findings such as anemia and even thrombocytopenia, during healthy pregnancy have changes in the hematological system, the coagulatory state and cell-mediated immunity. The 30\% - 50\% increase in intravascular volume generates edema and 
weight gain can contribute to joint pain [9] [10]. Paraclinics must have a correct interpretation; For example, in healthy pregnant women anemia is common in the third trimester due to hemodilution. Inflammatory markers may be elevated due to increased hepatic fibrinogen production, up to $10 \%$ may have thrombocytopenia [11]. Complement levels C3-C4 can also be increased by the liver and the level of proteinuria is increased due to increased renal blood flow [12].

It is a challenge for the nephrologist to differentiate preeclampsia from lupus nephritis or a lupus flare. Lupus nephritis flares during pregnancy can mimic preeclampsia and present increased proteinuria, hypertension, thrombocytopenia, and impaired renal function. Active lupus nephritis and preeclampsia can occur at the same time. Evidence of lupus activity in other organs can sometimes help distinguish lupus renal involvement from preeclampsia (see Table 2) [13]. The presence of glomerular hematuria in the urinary sediment and the presence of acanthocytes $>5 \%$ is categorical to define renal activity (Figure 2).

The clinical presentation of the case is a class VI lupus nephritis, requiring hemodialysis, resulting in a great challenge in its approach and treatment in the context of the high incidence of maternal-fetal complications. The intensity and frequency of hemodialysis are higher in order to guarantee an adequate evolution in the maternal-fetal binomial [14]. The concept of intensive dialysis is defined as more than 20 hours per week. In different series, it was shown that there is a higher neonatal survival rate compared to those who performed fewer hours per week (survival $75 \%$ vs $45 \%$ ) [15].

It allows maintaining a high-protein diet, guaranteeing nutritional requirements during pregnancy, [16] the characteristics of the dialysis fluid are very important, because the fetus requires 25 - 30 grams of calcium for the calcification of its skeleton, with a calcium bath of $2.5 \mathrm{mEq} / \mathrm{l}(1.25 \mathrm{mM})$ sufficient calcium is

Table 2. Differences of lupic nephritis-preeclampsia and hellp syndrome.

\begin{tabular}{cccc}
\hline & $\begin{array}{c}\text { ACTIVE LUPIC } \\
\text { NEPHRITIS }\end{array}$ & PREECLAMPSIA & $\begin{array}{c}\text { HELLP } \\
\text { SYNDROME }\end{array}$ \\
Gestational Age & $\begin{array}{c}\text { Any Gestational Age }- \\
\text { Includes Postpartum }\end{array}$ & $>20$ week & $>34$ Weeks \\
Creatinine Elevation & Common & Typically Absent & Rare \\
Thrombocytopenia & Present & Absent & Present \\
Neutropenia & Present & Absent & Absent \\
Complement Levels & Typically Decreased & Normal & Normal \\
Active Urinary Sediment & Common & Absent & Absent \\
Elevated Liver Enzymes & Absent & Absent & Present \\
Plasmatic Uric Acid Levels & Normal & High & Present \\
\hline
\end{tabular}

Active Urinary Sediment, Presence of Dysmorphic Hematuria $>50 \%$, Acantocytes $>5 \%$, The Presence Of A Hematic Cylinder. TAKEN FROM: G. Moroni, A. Doria, E. Giglio, E. Imbasciati, C. Tani, M. Zen, et al., Maternal Outcome In Pregnant Women With Lupus Nephritis. A Prospective Multicenter Study, J. Autoimmun. 74 (2016) 194-200. 


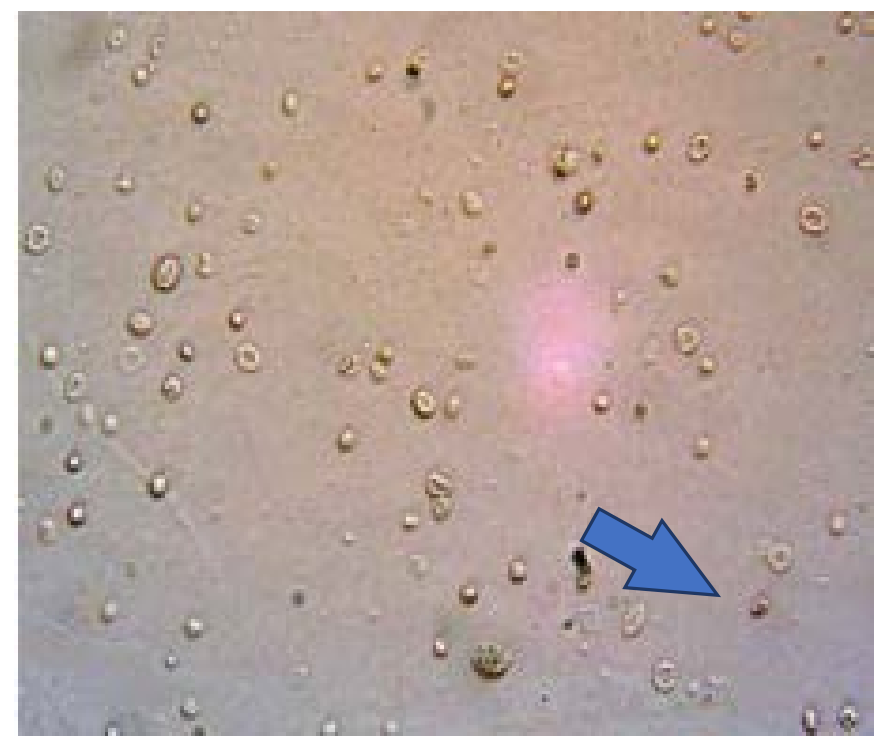

Figure 2. Dysmorphic hematuria, presence of acantocytes $(400 \times)$. TOMAD TAKEN FROM: Daza Lucas, De Rosa Marcelo, MD and De Rosa Graciela. Dysmorphic red blood cell formation, Cleveland Clinic Journal of Medicine January 2018, 85(1): 12-13; DOI: https://doi.org/10.3949/ccjm.85a.17029.

offered. Premature births are frequent and calcium fluxes are variable, recommending offering oral supplements.

The calcium in the dialysate should be low to reduce tissue calcification to a minimum, but sufficient to form the skeleton of the fetus. Patients who require phosphate binders have calcium carbonate as the only safe drug of this type in pregnancy, there are limited data regarding other phosphate binders during pregnancy (sevelamer, lanthanum carbonate and calcium acetate). Due to the intensity of dialysis, most patients become hypophosphatemic and binders are no necessary.

Regarding the management of secondary hyperparathyroidism, calcitriol can be used before and during pregnancy with the same indications as the general population. The use of calcimimetics such as cinecalcet is limited by few data on their safety in pregnancy. Serum calcium and phosphorus should be measured weekly, hypercalcemia can inhibit the parathyroid glands of the fetus and produce neonatal tetany [14].

With standard bathing, daily dialysis carries the theoretical risk of producing metabolic alkalosis, serum bicarbonate in normal pregnancy is $18-20 \mathrm{mmol} / \mathrm{l}$. A dialysis bath with $25 \mathrm{mmol}(\mathrm{Mm})$ of bicarbonate is usually effective in preventing alkalosis [14]. The estimated weight gain for pregnant women is approximately 11.5 to $16 \mathrm{~kg}$ in the first trimester, but only $1.6 \mathrm{~kg}$ of this total gain is gained during pregnancy. There is a $50 \%$ increase in blood volume, but vasodilation normally prevents the development of hypertension. The physician should perform a careful weekly evaluation including: Weight, blood pressure, and presence of edema, to determine fluid overload. It can be difficult to differentiate between excess fluid gained between dialysis sessions and pregnancy-associated 
weight gain. Dry weight increases throughout pregnancy and should increase by approximately $0.5 \mathrm{~kg} /$ week during the second and third trimesters, however, dry weight gain during pregnancy is dynamic and must be continually reassessed and adjusted based on pressure. Blood pressure, hydration and nutritional status of the patient. The ulfiltration rate must be individualized [17]. Heparinization is performed with conventional doses because heparin does not cross the placental barrier.

Anemia is associated with premature births and low birth weight, optimal hemoglobin levels have not been established in this group of patients. Treatment of anemia in pregnant dialysis patients is the same as that of non-pregnant patients, consisting of maintaining adequate iron stores and treating with erythropoiesis-stimulating agents to maintain adequate red blood cell mass. Physiologic changes and the demands of pregnancy can lead to increased anemia. For pregnant patients, a target of $10-11 \mathrm{~g} / \mathrm{dl}$ could be chosen [16].

During a normal pregnancy, a woman requires $700-1150 \mathrm{mg}$ of iron. Daily hemodialysis increases the losses of this element beyond the usual amounts required during pregnancy. There is a high rate of transfer to the fetus, especially after 30 weeks, the FDA has classified ferric gluconate and iron sucrose in category B of risk during pregnancy [17] (Table 3).

\section{Treatment}

The management of lupus nephritis during pregnancy does not differ in terms of the specific principles and objectives of non-pregnant women [17].

Appropriate preconception counseling must be mandatory to establish the situations that increase the risk of complications for the mother and potential risks to the offspring that contraindicate pregnancy (Table 4). Once the state of pregnancy has been established, the presence of conditions that predict a highrisk pregnancy make it necessary to implement appropriate measures from the early stages, resorting to the consultation and advice of an appropriate multidisciplinary team [18].

Among the aims of treatment it is necessary to prevent the development of outbreaks of the disease during the course of pregnancy, keep the disease inactive, identify potential complications of pregnancy and those related to pharmacological treatment, guaranteeing fetal well-being [19].

Although the use of scales to assess disease activity and systemic involvement have not been validated in pregnant patients, they can identify signs of symptoms of disease reactivation and consider the presence of complications related to pregnancy that could simulate reactivation of the lupus disease.

General intervention measures continue to be a fundamental part of the comprehensive management of these patients. Control of cardiovascular risk factors, nutritional status, and overweight control are essential.

Thromboembolic prophylaxis with acetylsalicylic acid at a dose of $100 \mathrm{mg}$ per day is recommended and is safe in pregnancy with the additional benefit shown in reducing the risk of preeclampsia [20]. 
Table 3. Recommendations for the management of pregnant women on dialysis.

\begin{tabular}{|c|c|}
\hline FACTOR & RECOMMENDATIONS \\
\hline ANEMIA & $\begin{array}{l}10-11 \mathrm{gr} / \mathrm{Dl} \text { - Requires An Increase } \\
\text { In Erythropoietin Dose Of 50\% - 100\% }\end{array}$ \\
\hline IRON SATURATION & $\begin{array}{l}\text { Maintain Intravenous Iron With A Saturation } \\
>30 \% \text { - Administer In Small Doses }\end{array}$ \\
\hline FOLIC ACID & $1 \mathrm{mg} /$ Day \\
\hline $\begin{array}{l}\text { HYPERTENSION/ } \\
\text { HEMODYNAMICS }\end{array}$ & $\begin{array}{l}\text { Avoiding Maternal Hypotension Or Volume } \\
\text { Depletion Requires Close And Clinical Follow-Up } \\
\text { During The Second And Third Trimesters. }\end{array}$ \\
\hline & $\begin{array}{c}\text { Biocompatible Dialyzer - Single Use } \\
\text { Avoid Metabolic Alkalosis } 25 \mathrm{Meq} \mathrm{HCO}_{3}\end{array}$ \\
\hline DIALYSIS PRESCRIPTION & $\begin{array}{c}\text { Avoid Hypokalemia Use } 3 \text { - } 4 \text { Meq Of Potassium } \\
\text { Add Phosphorus To The Dialysate To Maintain } \\
\text { Phosphorus } 4 \text { - } 5 \mathrm{Mg} / \mathrm{Dl}\end{array}$ \\
\hline BUN PREDIALYSIS & Maintain Levels Below 45 - $50 \mathrm{Mg} / \mathrm{Dl}$ \\
\hline TREATMENT FREQUENCY & $\begin{array}{l}5 \text { - } 6 \text { Times Per Week - Daily Nocturnal } \\
\text { Hemodialysis With Hemodiafiltration If Possible }\end{array}$ \\
\hline \multicolumn{2}{|l|}{ NUTRITION } \\
\hline CONSUMPTION PROTEINS & $\begin{array}{c}1.5 \mathrm{G} / \mathrm{Kg} / \text { Day In Hemodialysis - } 1.8 \mathrm{G} / \mathrm{Kg} / \text { Day } \\
\text { In Peritoneal Dialysis }\end{array}$ \\
\hline CONSUMPTION CALORIES & $30-35 \mathrm{Kcal} / \mathrm{Kg} / \mathrm{Day}$ \\
\hline CALCIUM & $\begin{array}{c}1500 \mathrm{Mg} / \text { Day Usually Achieved With } 2.5 \mathrm{meq} / \mathrm{L} \\
\text { Dialysed Calcium -Measured And Supplemented With } \\
25 \mathrm{OH} \text { Vitamin D Every Trimester }\end{array}$ \\
\hline MATCH & Oral Or Could Be Added To Dialysate \\
\hline VITAMINS & $\begin{array}{c}\text { Vitamin C - Thiamine - Riboflavin - Niacin - Vitamin } \\
\text { B6-Folate }\end{array}$ \\
\hline $\begin{array}{l}\text { OBSTETRIC/FETAL } \\
\text { MONITORING }\end{array}$ & $\begin{array}{c}\text { Stress-Free Test, Ultrasound, } \\
\text { Labor Termination And Neonatal Care }\end{array}$ \\
\hline
\end{tabular}

TAKEN FROM: Giatras L, Levy do, Malone FD, et al. Pregnancy during dialysis nephrol Dial 1998, 13: 3266.

Table 4. Contraindications to pregnancy in women with lupus.

- Severe Pulmonary Hypertension

- Severe Restrictive Lung Disease (Fvc $<1$ Liter)

- Heart Failure

- Chronic Kidney Disease With Creatinine Greater Than 2 Mg/Dl

- Severe Preeclampsia Or Previous Hellp.

- Cvd In The Previous 6 Months.

- Severe Lupus Flare In The Previous 6 Months.

FVC: Forced Vital Capacity. CVD: Brain Vascular Disease. TAKEN FROM: Ugarte A, Villar I, Ruiz-Irastorza G. Management of pregnancy in patients with systemic lupus erythematosus. Rev Clin Esp 2012; 212 (10): 491-98. 
The treatment of the activity of the disease in its oligosymptomatic forms can be done with antimalarials and/or NSAIDs (using the latter until the 20th week of pregnancy due to the risk of preterm delivery, early closure of the arterial duct and oligohydramnios).

Systemic corticosteroids can be used at the lowest doses and for the shortest time possible, for the management of disease activity or flares, with a low risk of fetal toxicity; They are of choice, prednisone, prednisolone that are inactivated in more than $90 \%$ by placental $11 \beta$-hydroxysteroid dehydrogenase, the exceptions are betamethasone and dexamethasone, which cross the placental barrier in high doses, so the latter are only indicated for induce lung maturation in the fetus. The use of supplemental calcium in pregnant women receiving systemic corticosteroids is likewise a recommended strategy.

Within the recommended antimalarials hydroxychloroquine or change to this if it was not previously received; Its use is related to better maternal-fetal outcomes and a reduction in thrombotic risk and prevention of the development of preeclampsia have been described [21].

Immunosuppressive drugs such as cyclophosphamide and mycophenolate are contraindicated in pregnancy due to their teratogenicity. Azathioprine at a maximum dose of $2 \mathrm{mg} / \mathrm{kg} /$ day has a good safety profile according to the different series, however, it has category D (FDA) and is used as a steroid-sparing drug in severe forms. Ultrasound monitoring is recommended since its prolonged use has been related to intrauterine growth retardation. tacrolimus in the treatment of lupus nephritis [22]. Tacrolimus has data in transplant registries suggesting that tacrolimus and cyclosporine are not associated with teratogenicity, and a small series of cases supports the role of tacrolimus in the treatment of lupus nephritis [23]. However, calcineurin inhibitors may be associated with an increased incidence of hypertension and gestational diabetes [24]. Calcineurin inhibitor metabolism increases during pregnancy and doses are often required higher to maintain pre-pregnancy plasma concentrations.

Regarding the use of biological agents such as tumor necrosis factor inhibitors, there are still doubts about their safety in pregnancy, some observational data with small sizes suggest that they could be useful in very early stages of pregnancy. There is agreement that more data is lacking to recommend its generalized use and it is only recommended in particular cases when other options are not available [25] [26].

The following table summarizes the main characteristics of the immunosuppressant used in the treatment of lupus nephritis (Table 5).

Table 5. Main characteristics of the immunosuppressors used in the treatment of lupic nephritis.

\begin{tabular}{ccccc}
\hline \multirow{2}{*}{ DRUGS } & MECHANISM OF ACTION & $\begin{array}{c}\text { TOXICITY IN } \\
\text { PREGNANCY }\end{array}$ & COMMENTS & $\begin{array}{c}\text { CATEGORY } \\
\text { US FDA }\end{array}$ \\
\hline METHOTREXATE & $\begin{array}{c}\text { Inhibits DNA synthesis by } \\
\text { inhibition of folic acid reductase }\end{array}$ & $\begin{array}{c}\text { Congenital } \\
\text { malformations }\end{array}$ & Induces fetal death & X \\
\hline
\end{tabular}




\begin{tabular}{cc}
\hline HIDROXICLOROQUINE $\quad \begin{array}{c}\text { The mechanisms that explain } \\
\text { its immunomodulatory } \\
\text { effect are unclear. }\end{array}$
\end{tabular}

MYCOPHENOLATE

TACROLYMUS

AZATHIOPRINE

CYCLOPHOSPHAMIDE

ADALIMUMAB INFLIXIMAB

\section{RITUXIMAB}

Blocks DNA synthesis through inhibition of IMPDH

Calcineurin inhibitor inhibits T lymphocyte activation

Inhibits DNA synthesis by antagonism with purines

Blocking DNA replication and RNA transcription through the formation of covalent bonds with alkyl groups

Chimeric monoclonal antibody inhibits tumor necrosis factor activity.

Monoclonal antibody antti CD20 reduces $\mathrm{B}$ lymphocytes
Teratogenic effects

have not been proven.

\section{Congenital}

malformation and

losses 1st trimester

Nephrotoxic at high doses, hypertension, gestational diabetes

Intrauterine growth retardation

Fetal loss

Not known toxicity

Neonatal cytopenia
Most used drug in

which no effects have

been shown in pregnancy

C

Its active metabolite

is mycophenolic acid

D

Requires high doses to achieve effect and low serum levels to reduce nephrotoxicity

The fetus cannot metabolize the enzyme to its active 6-MMP form.

Fetal death

D

IgG molecules do not

cross the placenta

in the first trimester.

B

Greater risk of infection.

IgG molecules do not

cross the placenta in the

first trimester

IMPDH: inosine monophosphate dehydrogenase; 6-MMP: 6-methylmecarptopurine Categories US FDA A: Absence of fetal toxicity in controlled studies. B: Animal studies have not shown dangerous effects, data is scarce in humans. Category C: Animal studies have shown evidence of possible toxic effects on the fetus. Limited human data, however the potential benefit may justify the risk. D: Post-marketing research data shows risk to the fetus, however the potential benefit may be greater. X: Research in animals or humans and post-marketing reports have shown risk to the fetus, which clearly outweighs any possible benefit. TAKEN FROM: 1-E. Ucara, G. Oraab, M.P. Grandec, F. Marcod, M. Imazd, M. López-Valverdeb and J.M. Aranburua. Management of systemic lupus erythematosus during pregnancy. Rev Esp Reumatol. 2003; 30 (4): 155-62. 2-M. Ostensen, M. Lockshin, A. Doria, G. Valesini, P. Meroni, C. Gordon, A. Brucato and A. Tincani. Update on safety during pregnancy of biological agents and some immunosuppressive anti-rheumatic drugs. Rheumatology 2008; 47: 28-31. doi: 10.1093/rheumatology/ken168.

\section{Conclusions}

Kidney involvement from lupus can affect the health of both pregnant women and their babies. For this reason, multidisciplinary teams should be available to all women with kidney disease to offer advice before pregnancy and to support, monitor and treat women with kidney disease during pregnancy and after delivery.

Fortunately, studies are underway in existing glomerulonephritis collaborative groups, including Cure Glomerulonephropathy, which will hopefully provide important data to help guide young women in making this life-changing decision.

\section{Informed Consent}

Written informed consent was obtained from the patient for the publication of 
this clinical case, there are no images of the patient in this manuscript

\section{Conflicts of Interest}

The authors declare that they have no potential conflict of interest related to the contents of this article.

\section{References}

[1] Gonzalez Suarez, M.L., Kattah, A., Grande, J.P. and Garovic, V. (2019) Renal Disorders in Pregnancy: Core Curriculum 2019. American Journal of Kidney Diseases, 73, 119-130. https://doi.org/10.1053/j.ajkd.2018.06.006

[2] Smyth, A., Oliveira, G.H., Lahr, B.D., et al. (2010) A Systematic Review and Meta-Analysis of Pregnancy Outcomes in Patients with Systemic Lupus Erythematosus and Lupus Nephritis. Clinical Journal of the American Society of Nephrology, 5, 2060-2068. https://doi.org/10.2215/CJN.00240110

[3] Shahir, A.K., Briggs, N., Katsoulis, J. and Levidiotis, V. (2013) An Observational Outcomes Study from 1966-2008, Examining Pregnancy and Neonatal Outcomes from Dialysed Women Using Data from the ANZDATA Registry. Nephrology, 18, 276 284. https://doi.org/10.1111/nep.12044

[4] Chen, Y.E., Korbet, S.M., Katz, R.S., Schwartz, M.M. and Lewis, E.J. (2008) Collaborative Study Group. Value of a Complete or Partial Remission in Severe Lupus Nephritis. Clinical Journal of the American Society of Nephrology, 3, 46-53. https://doi.org/10.2215/CJN.03280807

[5] Buyon, J.P., Kim, M.Y., Guerra, M.M., et al. (2015) Predictors of Pregnancy Outcomes in Patients with Lupus: A Cohort Study. Annals of Internal Medicine, 163, 153-163. https://doi.org/10.7326/M14-2235

[6] Moroni, G., Doria, A., Giglio, E., et al. (2016) Maternal Outcome in Pregnant Women with Lupus Nephritis. A Prospective Multicenter Study. Journal of Autoimmunity, 74, 194-200. https://doi.org/10.1016/j.jaut.2016.06.012

[7] Clowse, M.E.B., Jamison, M., Myers, E., et al. (2008) A National Study of the Complications of Lupus in Pregnancy. American Journal of Obstetrics \& Gynecology, 199, 127.E1-127.E6. https://doi.org/10.1016/j.ajog.2008.03.012

[8] Doria, A., Tincani, A. and Lockshin, M. (2008) Challenges of Lupus Pregnancies. Rheumatology, 47, iii9-iii12. https://doi.org/10.1093/rheumatology/ken151

[9] Andreoli, L., Fredi, M., Nalli, C., Reggia, R., Lojacono, A., Motta, M., et al. (2012) Pregnancy Implications for Systemic Lupus Erythematosus and the Antiphospholipid Syndrome. Journal of Autoimmunity, 38, J197-J208.

https://doi.org/10.1016/j.jaut.2011.11.010

[10] Knight, C.L. and Nelson-Piercy, C. (2017) Management of Systemic Lupus Erythematosus during Pregnancy: Challenges and Solutions. Open Access Rheumatology: Research and Reviews, 9, 37-53. https://doi.org/10.2147/OARRR.S87828

[11] Velo-Garcia, A., Castro, S.G. and Isenberg, D.A. (2016) The Diagnosis and Management of the Haematologic Manifestations of Lupus. Journal of Autoimmunity, 74, 139-160. https://doi.org/10.1016/j.jaut.2016.07.001

[12] Ruiz-Irastorza, G. and Khamashta, M.A. (2011) Lupus and Pregnancy: Integrating Clues from the Bench and Bedside. European Journal of Clinical Investigation, 41, 672-678. https://doi.org/10.1111/j.1365-2362.2010.02443.x

[13] Stanhope, T.J., White, W.M., Moder, K.G., Smyth, A. and Garovic, V.D. (2012) Ob- 
stetric Nephrology: Lupus and Lupus Nephritis in Pregnancy. Clinical Journal of the American Society of Nephrology, 7, 2089-2099.

https://doi.org/10.2215/CJN.12441211

[14] Okundaye, I.B., Abrinco, P. and Hou, S. (1998) Registry for Pregnancy in Dialysis Patients. American Journal of Kidney Diseases, 31, 766-773.

https://doi.org/10.1016/S0272-6386(98)70044-7

[15] Hou, S. (2010) Pregnancy in Women Treated with Dialysis: Lessons from a Large Series over 20 Years. American Journal of Kidney Diseases, 56, 5-6. https://doi.org/10.1053/j.ajkd.2010.05.002

[16] Nadeau-Fredette, A.C., et al. (2013) End-Stage Renal Disease and Pregnancy. Advances in Chronic Kidney Disease, 20, 246-252.

https://doi.org/10.1053/j.ackd.2013.01.010

[17] Giatras, L., Levy, D.P., Malone, F.D., et al. (1998) Pregnancy during Dialysis: Case Report and Management Guidelines. Nephrology Dialysis Transplantation, 13, 3266-3272. https://doi.org/10.1093/ndt/13.12.3266

[18] Ugarte, A., Villar, I. and Ruiz-Irastorza, G. (2012) Manejo del embarazo en pacientes con lupus eritematoso sistémico. Revista Clínica Española, 212, 491-498.

https://doi.org/10.1016/j.rce.2011.11.003

[19] Stojan, G. and Baer, A.N. (2012) Flares of Systemic Lupus Erythematosus during Pregnancy and the Puerperium: Prevention, Diagnosis and Management. Expert Review of Clinical Immunology, 8, 439-453. https://doi.org/10.1586/eci.12.36

[20] Ponticelli, C. and Moroni, G. (2015) Immunosuppression in Pregnant Women with Systemic Lupus Erythematosus. Expert Review of Clinical Immunology, 11, 549-552. https://doi.org/10.1586/1744666X.2015.1033404

[21] Rovin, B.H. and Parikh, S.V. (2014) Lupus Nephritis: The Evolving Role of Novel Therapeutics. American Journal of Kidney Diseases, 63, 677-690.

https://doi.org/10.1053/j.ajkd.2013.11.023

[22] Hannah, J., Casian, A. and D’Cruz, D. (2016) Tacrolimus Use in Lupus Nephritis: A Systematic Review and Meta Analysis. Autoimmunity Reviews, 15, 93-101. https://doi.org/10.1016/j.autrev.2015.09.006

[23] Ucara, E., Oraab, G., Grandec, M.P., Marcod, F., Imazd, M., López-Valverdeb, M. and Aranburua, J.M. (2003) Manejo del lupus eritematoso sistemico durante el embarazo. Revista Española de Reumatología, 30, 155-162.

[24] Ostensen, M., Lockshin, M., Doria, A., Valesini, G., Meroni, P., Gordon, C., Brucato, A. and Tincani, A. (2008) Update on Safety during Pregnancy of Biological Agents and Some Immunosuppressive Anti-Rheumatic Drugs. Rheumatology, 47, iii28-iii31. https://doi.org/10.1093/rheumatology/ken168

[25] Ostensen, M. and Forger, F. (2011) Treatment with Biologics of Pregnant Patients with Rheumatic Diseases. Current Opinion in Rheumatology, 23, 293-298. https://doi.org/10.1097/BOR.0b013e328344a732

[26] Verstappen, S.M., King, Y., Watson, K.D., Symmons, D.P. and Hyrich, K.L. (2011) Anti-TNF Therapies and Pregnancy: Outcome of 130 Pregnancies in the British Society for Rheumatology Biologics Register. Annals of the Rheumatic Diseases, 70, 823-826. https://doi.org/10.1136/ard.2010.140822 